\title{
Nephritogenicity of Antibodies to Proteoglycans of the Glomerular Basement Membrane-I
}

\author{
Hirofumi Makino, John T. Gibbons, M. Kumudavalli Reddy, and Yashpal S. Kanwar \\ Department of Pathology, Northwestern University Medical School, Chicago, Illinois 60611
}

\begin{abstract}
We investigated nephritogenic potential of antibodies to heparan sulfate-proteoglycan of glomerular basement membrane. Glomeruli were isolated, basement membranes were prepared, proteoglycans extracted, and purified core protein was obtained. We immunized rabbits with the core protein, IgG fraction prepared from the antisera and specificity of the antibody determined. A single immunoprecipitin line in agar diffusion plate and a single band $(\sim 18,000$ mol wt) on the immunoblot autoradiograms were visualized. The antibody showed precise reactivity with the glomerular basement membranes. The clearance studies indicated that $\sim 75 \%$ of the radioiodinated antibody disappeared from circulation within $1 \mathrm{~h}$ and 1-2\% bound to the kidney, For nephritogenicity experiments, the antibody was intravenously administered into rats and we examined their kidneys at $1 \mathrm{~h}$ to $24 \mathrm{~d}$ later. A linear immunofluorescence of glomerular basement membranes was observed with rabbit IgG at all times while that of $C_{3}$ until the 10th day. Early morphologic changes included glomerular infiltration of polymorphonuclear leukocytes with focal exfoliation of endothelium. The leukocytic infiltration subsided by the third day and was followed by progressive thickening of basement membranes, focal mesangial cell proliferation, increase in mesangial matrix, and accumulation of monocytes. Focal knob-like thickening of glomerular basement membrane was observed from the 15th day onward. Regularly-spaced electrondense deposits were seen in the lamina rara interna and externa of glomerular basement membranes and persisted throughout the investigatory period. No significant proteinuria was observed at any stage of the experiment. These findings suggest that the antibodies to the basement membrane heparan sulfate-proteoglycan are nephrotoxic but possess weak nephritogenic potential.
\end{abstract}

\section{Introduction}

About $35 \mathrm{yr}$ ago, Krakower and Greenspon (1) described the localization of the nephrotoxic antigen of Masugi nephritis (2) within the isolated rat renal glomerulus. Since then, extensive investigatory efforts have firmly established that the glomerular

Address reprint requests and correspondence to Dr. Kanwar, Department of Pathology, Northwestern University Medical School, 303 E. Chicago Ave., Chicago, IL 60611.

Received for publication 25 March 1985 and in revised form 5 September 1985

J. Clin. Invest.

(c) The American Society for Clinical Investigation, Inc.

$0021-9738 / 86 / 01 / 0142 / 15 \quad \$ 1.00$

Volume 77, January 1986, 142-156 basement membrane (GBM), ${ }^{1}$ as a whole, is highly antigenic (1, 3-5). Intravenous administration of the GBM antiserum to rats is followed by a fulminating disease process, conveniently termed nephrotoxic serum nephritis (NTN). The NTN has a biphasic course, i.e., a heterologous and an autologous phase, and is superbly detailed in a recent review by Wilson (6). Briefly, in the heterologous phase, injected heterologous antibodies bind to the GBM soon after their administration and cause complement activation/deposition $(7,8)$, polymorphonuclear leukocyte (PMN) infiltration, and endothelial exfoliation (9-13) and proteinuria $(14,15)$. The autologous phase, which ensues after a week or so, is characterized by a humoral production of host IgG antibodies to the GBM (16), further deposition of $C_{3}(16$, 17), and proliferation of the glomerular cells with accumulation of monocytes $(17,18)$, and leading to an accentuated proteinuric response $(15,19)$.

The GBM is made up of a wide variety of collagenous and noncollagenous glycoproteins $(20,21)$. Among the well described glycoproteins of the GBM are type IV collagen (22), laminin (23), entactin (24), and heparan sulfate-proteoglycans $(25,26)$. The exact nature of the antigenic portion of GBM from which nephrotoxic antibodies could be conceivably derived is somewhat ill-defined (6). So far, the antibodies against type IV collagen and laminin have been raised but they are proven to be weakly nephrotoxic (27-29). Moreover, the antigenic components within the GBM that bind the nephrotoxic antibodies have not been clearly identified.

Heparan sulfate-proteoglycan (HS-PG) seems to be another essential component of the GBM, which to a large extent endows the permselective properties to the renal glomerulus (30). In this investigation we explored nephritogenicity of the antibodies, raised against the core-protein of the HS-PG isolated from purified rat GBM fractions.

\section{Methods}

Isolation and purification of $H S-P G$ from the GBM. Under ether anesthesia, both rat kidneys were perfused with Krebs-Ringer bicarbonate buffer containing $1 \%$ bovine serum albumin (BSA) and protease inhibitors via retrograde aortic route $(31,32)$. The renal cortices were dissected free, glomeruli were isolated (1), GBM fractions were prepared (33), and proteoglycans (PGs) were extracted from the GBMs in the presence of protease inhibitors for $48 \mathrm{~h}(26,34)$. Extracted PGs were fractionated and purified by centrifugation $\left(35,000 \mathrm{rpm}\right.$ for $72 \mathrm{~h}$ at $\left.8^{\circ} \mathrm{C}\right)$ on a $\mathrm{CsCl}$ gradient with an adjusted initial density of $1.42 \mathrm{~g} / \mathrm{ml}(26,34)$. Five equal fractions $\left(D_{1}-D_{5}\right.$, from bottom to top) were made and $D_{1}$ fraction con-

1. Abbreviations used in this paper: FITC, fluorescein isothiocyanate; GAG(s), glycosaminoglycan(s); GBM, glomerular basement membrane; HS-PG, heparan sulfate-proteoglycan; LRE, lamina rara externa; LRI, lamina rare interna; NCA, nitrocellulose acetate; NTN, nephrotoxic serum nephritis; PAGE, polyacrylamide gel electrophoresis; PG(s), proteoglycan(s). 
tained most of the HS-PG ( $\sim 70 \%$; ref. 26$)$ collected. The latter fraction was extensively dialyzed against ice cold distilled water, then concentrated in a diaflow membrane ultrafiltration apparatus, aliquoted, and stored at $-20^{\circ} \mathrm{C}$.

Characterization of the antigen (HS-PG). Amino acid analyses (26), protein (35), and sialic acid (36) contents were determined on the $D_{1}$ fraction containing the HS-PG. The glycosaminoglycans (GAGs) characterization was carried out by cellulose acetate electrophoresis after alkaline hydrolysis of the core protein of HS-PG (37). The molecular weight of the core protein of HS-PG was determined by sodium dodecyl sulfate (SDS)-polyacrylamide gel electrophoresis (PAGE) (38) after enzymatic degradation of GAG chains with purified heparitinase (gift from Dr. Linker, University of Utah, Salt Lake City, UT. Ref. \#39).

Preparation and purification of anti-HS-PG antibody. Rabbits were immunized with multiple subcutaneous injections of HS-PG containing 3-4 mg of protein (obtained from $\sim 250$ rat kidneys), boosted every 2 wk, bled 6-8 wk after the primary immunization, and their sera were collected. The antisera were decomplemented by heating at $56^{\circ} \mathrm{C}$ for 30 min and were absorbed with freshly harvested erythrocytes. The IgGenriched fraction was obtained by repeated precipitation with varying concentrations of ammonium sulfate (40) and its purity was ascertained by immunofixation-electrophoresis (4i). For clearance and binding studies IgG fraction was further purified by DEAE-cellulose chromatography (42).

Specificity of the antibody. The specificity of the antibody was determined by double immunodiffusion in $1 \%$ agar according to the method of Ouchterlony (43). Cross-reactivity of the antibody with enzymatic digests of the GBM was also tested by treating GBMs either with collagenase or pronase or trypsin. Specificity was further tested by SDS-PAGE and Western blotting techniques (44). Briefly, 1-5 $\mu \mathrm{g}$ of HS-PG was applied to $10 \%$ SDS-polyacrylamide gel electrophoresis and transferred to nitrocellulose acetate (NCA) paper by electroblotting. The NCA paper was then immersed in Tris-buffer saline solution containing antibody $(\sim 5 \mathrm{mg} / \mathrm{ml})$ and $5 \%$ BSA followed by extensive washing with Tris-buffer saline solution. The NCA paper was then soaked in TBS-BSA solution containing ${ }^{125} \mathrm{I}$-staphylococcus protein $\mathrm{A}\left(1 \times 10^{6} \mathrm{cpm}\right)$ for $30 \mathrm{~min}$ and dried at room temperature. The dried NCA paper was covered with XOmat film (Eastman Kodak Co., Rochester, NY), and the films were subsequently exposed for $4-5 \mathrm{~d}$ at $-70^{\circ} \mathrm{C}$ with intensifying screens and developed. Final verification of the specific reactivity of the antibody was determined by indirect immunofluorescence. The $4-\mu \mathrm{m}$-thick cryostat sections of the kidney and lungs were incubated with anti-HS-PG, washed with phosphate-buffered saline (PBS), and reincubated with fluorescein isothiocyanate (FITC) conjugated sheep anti-rabbit IgG and examined by immunofluorescent microscopy.

Antibody clearance and binding studies. The IgG fraction of the antibody and normal IgG were radioiodinated with ${ }^{125} \mathrm{I}-\mathrm{Na}$ by lactoperoxidase-glucose oxidase method as previously described (45). The free iodine was removed by exhaustive dialysis and Sephadex G-25 chromatography. After procuring the ${ }^{125} \mathrm{I}$-antibody, four sets of studies were carried out. In the first set, 36 rats, weighing $\sim 50 \mathrm{~g}$, received $2.5 \mathrm{mg}$ of antibody intravenously and were killed in batches of four at 10,20, and $30 \mathrm{~min} ; 1,2$, and $6 \mathrm{~h}$; and 1, 3, and $5 \mathrm{~d}$ after its administration. Before sacrifice the blood samples and kidney tissues were obtained for determining the radioactivity. We calculated the amount of radioactive antibody bound to the kidneys after flushing them with $0.15 \mathrm{M} \mathrm{NaCl}$ via retrograde aortic perfusion and expressed this amount as micrograms of ${ }^{125}$ I-antibody bound per gram of kidney tissue as follows: milligrams of ${ }^{125}$ I-antibody injected $X$ percent injected radioactivity in the kidney per gram of kidney tissue.

Next, we investigated dose-dependent antibody binding to the kidneys. The tissue samples were obtained $1 \mathrm{~h}$ after administration of the antibody; this interval seemed to be appropriate since by this time most of the antibody has been cleared from circulation and its binding to the kidney more or less equilibrated. A dose range of $0.0625-25 \mathrm{mg}$ was employed, kidney bound radioactivity was determined, and expressed as indicated above. We used 30 animals and killed them in groups of six per variable of the dosage. In the third set of experiments, the amount of antibody bound to the kidney was compared with the binding of normal IgG. Six animals were used in each group and a dose of $25 \mathrm{mg}$ of radioiodinated IgG fractions was employed. Lastly, to confirm the dose-dependent binding and precise localization of the antibody to the glomerular capillary wall, tissues from the second and third set of studies were processed for light microscopic autoradiography $(45,46) . \sim 36$ glomeruli from six rat tissues were analyzed in each of the six groups (five different dosages and a control). The glomeruli were photographed and printed to a final magnification of 1,500 . We counted the autoradiographic grains over the capillary wall. The area of the capillary wall was determined by point counting method as previously described (46). The grain density was computed by dividing the total grains by total area points. Finally, the mean grain density and standard deviation about the mean were determined.

Protocol of the nephritogenicity experiments with anti-HS-PG antibody. We used 42 female Fischer rats, weighing 50-60 g. 28 of these animals were given intravenous injections of $0.5 \mathrm{ml}$ saline containing $\sim 50 \mathrm{mg} / 100 \mathrm{~g}$ body weight of rabbit IgG-enriched fraction of anti-rat HS-PG, and 14 control rats received a similar amount of IgG obtained from normal rabbit serum. The preliminary studies, where varying concentrations of the antibody $(0-100 \mathrm{mg} / 100 \mathrm{~g}$ body weight $)$ were employed, indicated that a dose of $50 \mathrm{mg} / 100 \mathrm{~g}$ body weight would be the maximum amount that the animal could tolerate without dying. Also, the kinetics of binding and tissue autoradiographic data (see Results) suggested that this dose of the antibody seemed to have occupied almost all the available antigenic sites of the glomerular capillary wall. The animals were sacrificed in batches of four experimental and two controls at $1 \mathrm{~h}, 1,3,6,10,15$ and $24 \mathrm{~d}$ after administration of IgG enriched fractions. Before being killed, they were transferred to metabolic cages for 24-h urine collection with access to water ad lib. only. The urinary proteins were determined by biuret method (47) and the rats' kidneys were processed for direct immunofluorescent, light and electron microscopy.

Morphologic studies. Direct immunofluorescence studies were performed on 4- $\mu \mathrm{m}$-thick unfixed cryostat sections. The sections were airdried, washed with PBS buffer, and incubated with either of the following antisera: FITC anti-rabbit IgG, rat IgG, $\mathrm{C}_{3}$, and albumin (Cooper Biomedical, Inc., Malvern, PA) and examined by immunofluorescent microscopy. The intensity of fluorescence was graded on a $(-)$ to $(++++)$ scale. For light microscopy, renal cortical pieces were fixed in $10 \%$ formaldehyde, 4-5- $\mu \mathrm{m}$-thick sections were made and stained with periodic acid-Schiff(PAS) reagent. Kidney tissues, fixed either in $1 \%$ glutaraldehyde

Table I. Amino Acid Composition of $H S-P G$ of $G B M$

\begin{tabular}{lc}
\hline Amino acid & $D_{1}$ fraction \\
\hline Lysine & 73 \\
Histidine & 29 \\
Arginine & 68 \\
Aspartic acid & 84 \\
Threonine & 49 \\
Serine & 83 \\
Glutamic acid & 112 \\
Proline & 73 \\
Glycine & 137 \\
Alanine & 96 \\
Valine & 39 \\
Methionine & 4 \\
Isoleucine & 26 \\
Leucine & 62 \\
Tyrosine & 26 \\
Phenylalanine & 26 \\
\hline
\end{tabular}

* Residues per 1,000 amino acids. 


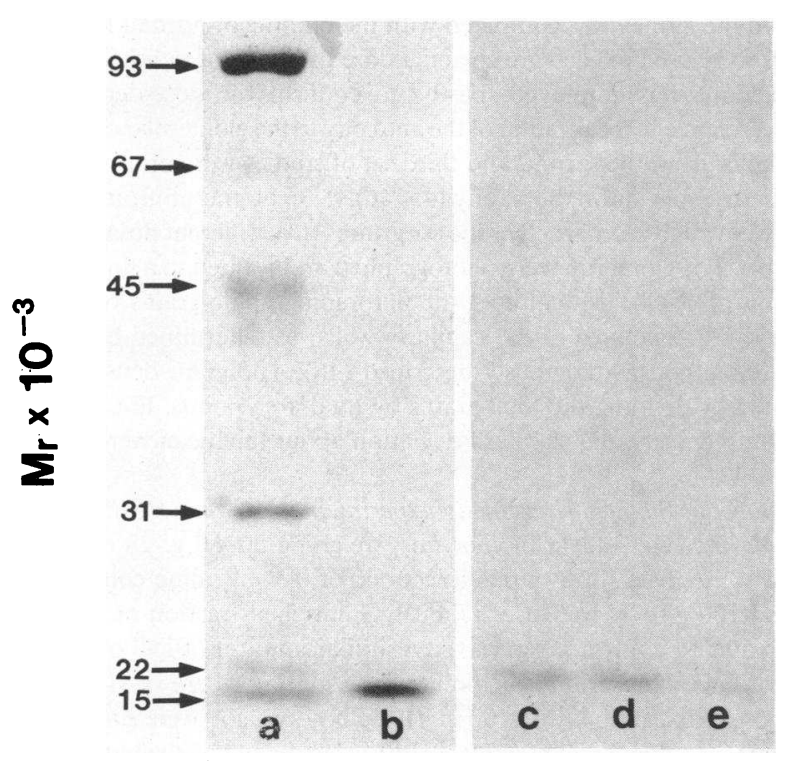

Figure 1. $\mathrm{NaDodSO}_{4} /$ polyacrylamide gel ( $\left.10 \%\right)$ electrophoresis. Lane $a$, molecular weight standards; lane $b$, core-protein of heparan sulfateproteoglycan. Lanes $c, d$, and $e$ are the autoradiograms of immunoblots of core-protein applied to the gel in concentrations of 5, 2.5, and $1.0 \mu \mathrm{g}$, respectively. A single band of core-protein with $M_{\mathrm{r}} \sim 18,000$ and corresponding solitary bands in the immunoblots are observed.

or $1 \%$ glutaraldehyde plus $0.2 \%$ tannic acid in $0.1 \mathrm{M}$ cacodylate buffer, $\mathrm{pH} 7.4$, were processed for electron microscopy $(31,32)$.

\section{Results}

Characterization of the antigen. Amino acid analysis of the $D_{1}$ fraction (Table I) was almost identical to the $D_{1}$ fraction proteoglycans extracted from the whole glomeruli as previously described (26). Absence of hydroxyproline and hydroxylysine in-

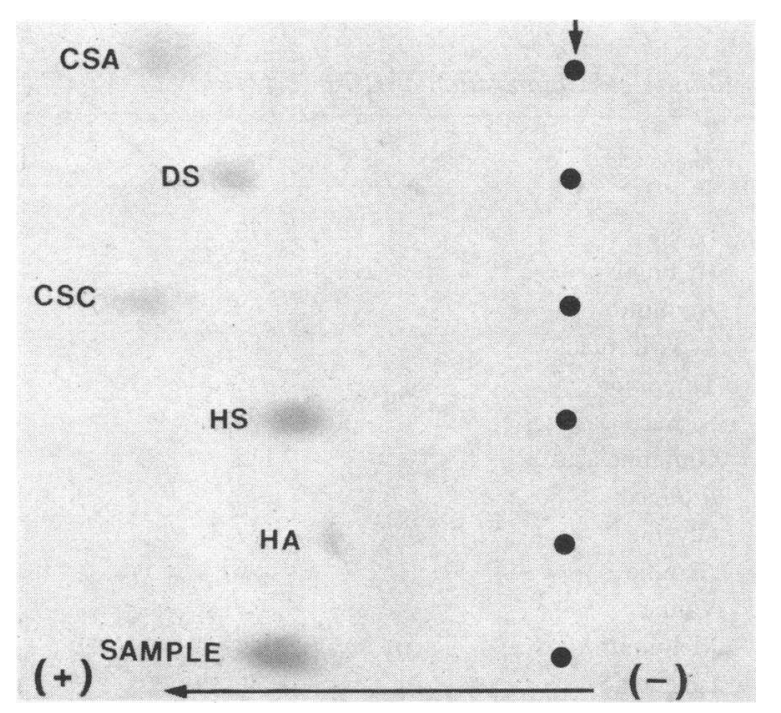

Figure 2. Cellulose acetate electrophoretograms of standards, which include chondroitin sulfates $\mathrm{A}(C S A)$ and $\mathrm{C}(C S C)$, dermatan sulfate $(D S)$, heparan sulfate $(H S)$, and hyaluronic acid $(H A)$. The sample that is a hydrolysate of $\mathrm{D}_{1}$ fraction of $\mathrm{CsCl}$ gradient has a single spot co-migrating with heparan sulfate standard.

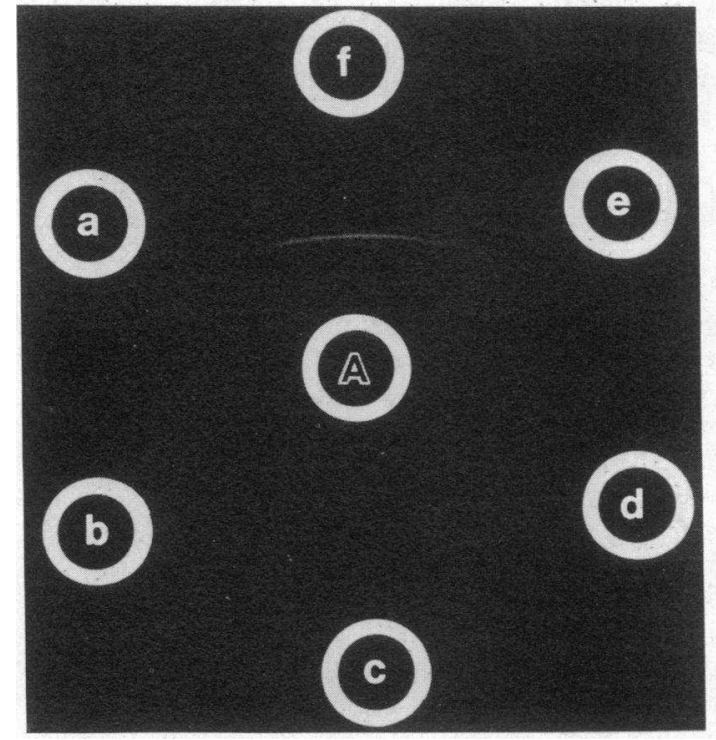

Figure 3. Ouchterlony immunodiffusion agar plate that includes antiHS-PG antibody in the center well $(A)$. The wells $a, b$, and $c$ contain collagenase, pronase, and tryptic digests of the GBM, respectively; and $d, e$, and $f$ contain bovine serum albumin, rabbit preimmune serum, and HS-PG, respectively. A single immunoprecipitin line is observed between the wells containing anti-HS-PG $(A)$ and HS-PG $(f)$.

dicated the noncollagenous nature of the glycoprotein; and lack of cystine residues suggested that it is not cross-linked via disulfide bridges to other basement membrane proteins. The estimated molecular weight of the core protein of HS-PG in the $D_{1}$ fraction appeared to be similar to what had been previously reported (26). A single band with a molecular weight of $\sim 18,000$ was visualized on SDS-PAGE (Fig. 1). The cellulose acetate electro-

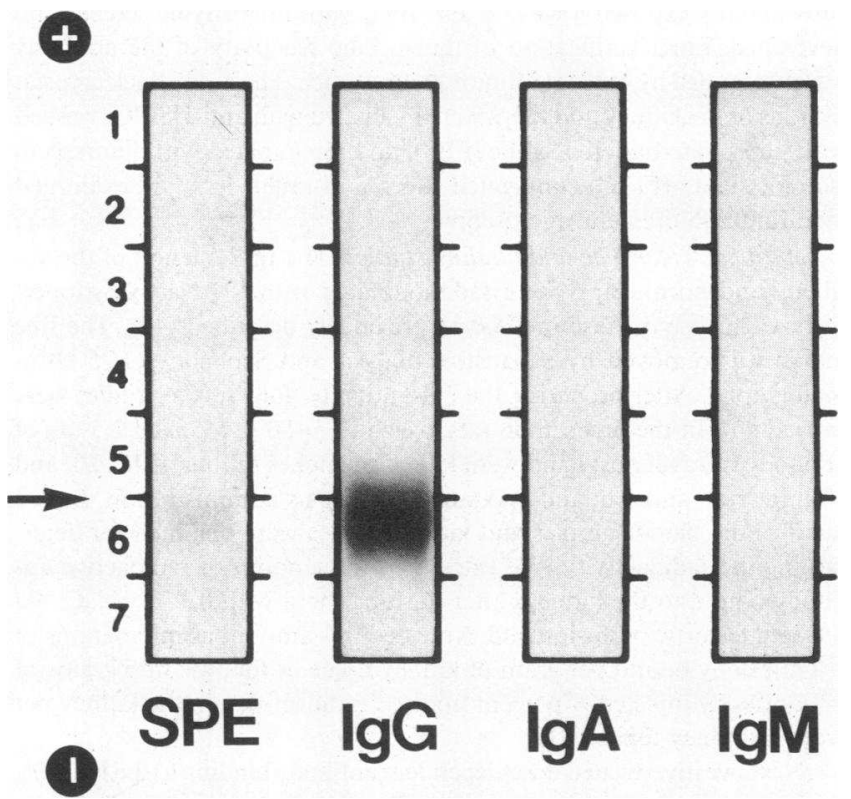

Figure 4. Immunofixation-electrophoresis of the final ammonium sulfate precipitate fraction of the antisera. The band in lane SPE simply indicates the migratory behavior of the fraction. The remaining template wells were incubated with respective anti-rabbit gammaglobulins. Note that the isolated fraction mainly contains IgG. The arrow denotes the point of application of the samples. 


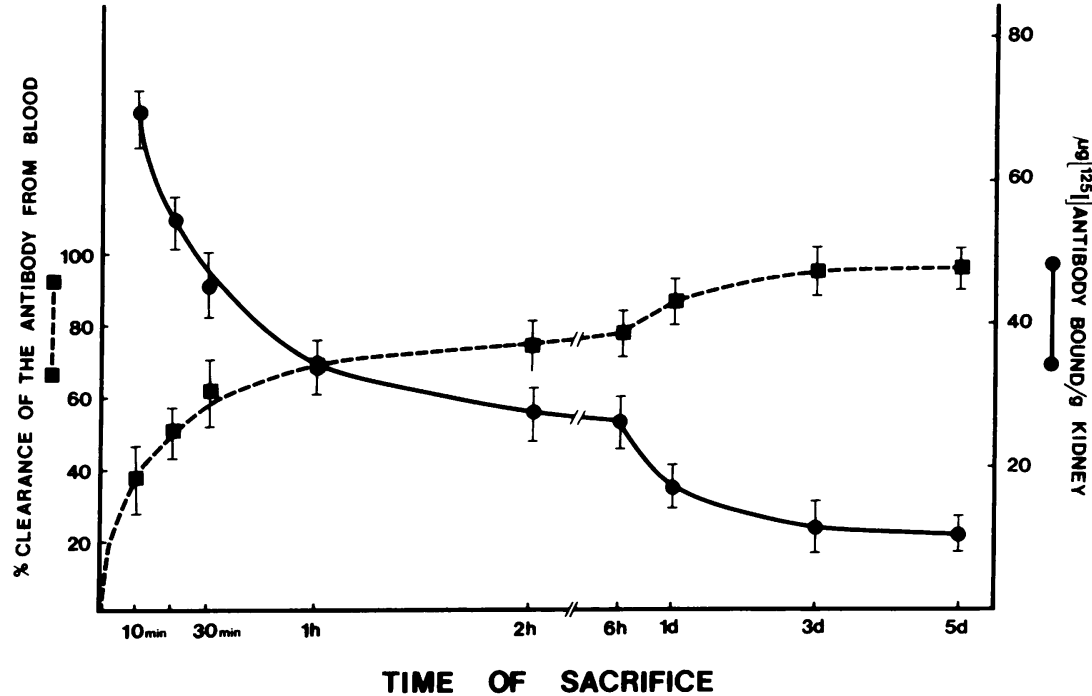

Figure 5. Percent clearance and the amount of radioiodinated antibody bound to kidney at various time intervals after its administration. phoresis of GAG chains of HS-PG revealed a single spot that co-migrated with heparan sulfate standard (Fig. 2) and was similar to what had been isolated from proteolytic digests of the whole GBMs (25). No sialic acid was detected, which indicates that no contaminating cell surface-associated sialoglycoproteins were present in the $D_{1}$ fraction. These data indicated an authentic isolation of HS-PG, the antigen, from the GBM fractions.

Specificity and purity of the antibody. In the Ouchterlony double immunodiffusion agar plates, only one precipitin line was observed between the wells containing IgG-enriched fraction of the antiserum and the antigen HS-PG (Fig. 3). No precipitin lines were seen between the walls containing the antiserum and normal serum, albumin, and collagenase, pronase, and tryptic digests of the GBM. Similarly, a single band corresponding to a molecular weight of $\sim 18,000$ was observed in the autoradiograms of the SDS-PAGE/Western blot, which indicates a high specificity of the antibody to the core protein of HS-PG of the GBM (Fig. 1). Finally, verification by indirect immunofluorescence studies confirmed the specific reactivity of the antibody. An intense immunofluorescence of the GBM was observed, with minimal staining in the mesangial regions of the glomerulus (Fig. $8 \mathrm{~A}$ ). We observed a somewhat lesser degree of fluorescence in the extraglomerular basement membranes including those of Bowman's capsule, tubules, and blood vessels. Pulmonary alveolar basement membranes exhibited a mild to moderate degree of reactivity of the antibody directed against the core protein of HS-PG of the GBM.

The immunofixation-electrophoretic data indicated a high degree of purity of the IgG contained in various fractions of the antibody. Interestingly enough, even the initial ammonium sulfate precipitated fractions of the antisera appeared to contain mostly the IgG (Fig. 4). In view of these findings, the antibody was considered suitable for the clearance, binding, and nephritogenicity experiments.

Clearance and binding experiment. $\sim 75 \%$ of the antibody rapidly cleared from circulation within $1 \mathrm{~h}$ followed by a gradual decline in the radioactivity over a period of $5 \mathrm{~d}$ (Fig. 5). Concomitantly, the antibody fixation seemed to reach equilibration by $1 \mathrm{~h}$, at which time $\sim 1.4 \%(\sim 35 \mu \mathrm{g})$ of the injected antibody $(2.5 \mathrm{mg})$ was bound to the kidney; and it slowly decreased to $0.5 \%$ by the fifth day (Fig. 5). The percent binding of anti-HS-
PG antibody seemed to be similar to those of anti-GBM (48, 49) or laminin antibodies (27). The degree of binding was proportional at lower dosages, ranging from 0.0625 to $0.25 \mathrm{mg}$, while it began to plateau to a certain degree at higher dosages (Fig. 6). At a dose of $25 \mathrm{mg} / 50 \mathrm{~g}$ body weight, the antibody occupied maximally all the glomerular capillary loops as visualized by tissue autoradiography (Fig. $7 A$ ). At lower doses, the autoradiographic grain density decreased dramatically (Fig. $7 B$ and $C$; Table II). In control animals injected with equivalent amounts of normal ${ }^{125} \mathrm{I}-\mathrm{IgG}(25 \mathrm{mg} / 50 \mathrm{~g}$ body weight), the binding was drastically less, i.e., the amount of normal ${ }^{125} \mathrm{I}$-IgG bound was $14.5 \mu \mathrm{g}$ while that of antibody-IgG fraction was $195 \mu \mathrm{g} / \mathrm{g}$ of kidney tissue. Furthermore, the autoradiography, the technique that probably reflects far more accurate and precise specific binding of ligands than simple radiocounting, indicated the binding of the antibody as compared with normal IgG fraction in a ratio of 32:1 (Fig. $7 \mathrm{D}$ and Table II). Finally, since the autoradiographic grains were visualized only on the glomerular capillaries, it meant that $(a)$ the antibody retained its reactivity

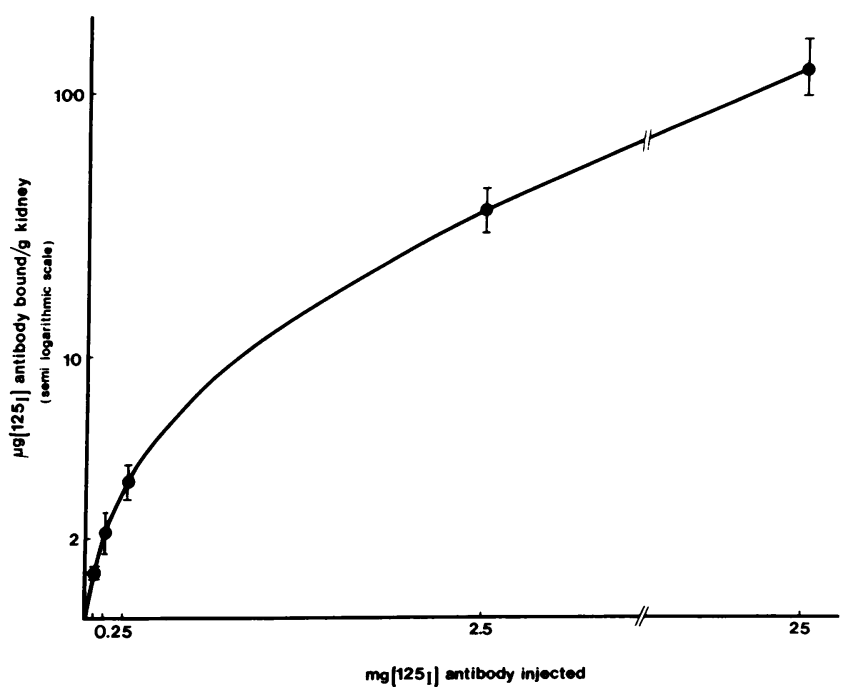

Figure 6. Dose-dependent binding of radioiodinated antibody to the kidney at $1 \mathrm{~h}$ after its administration. 

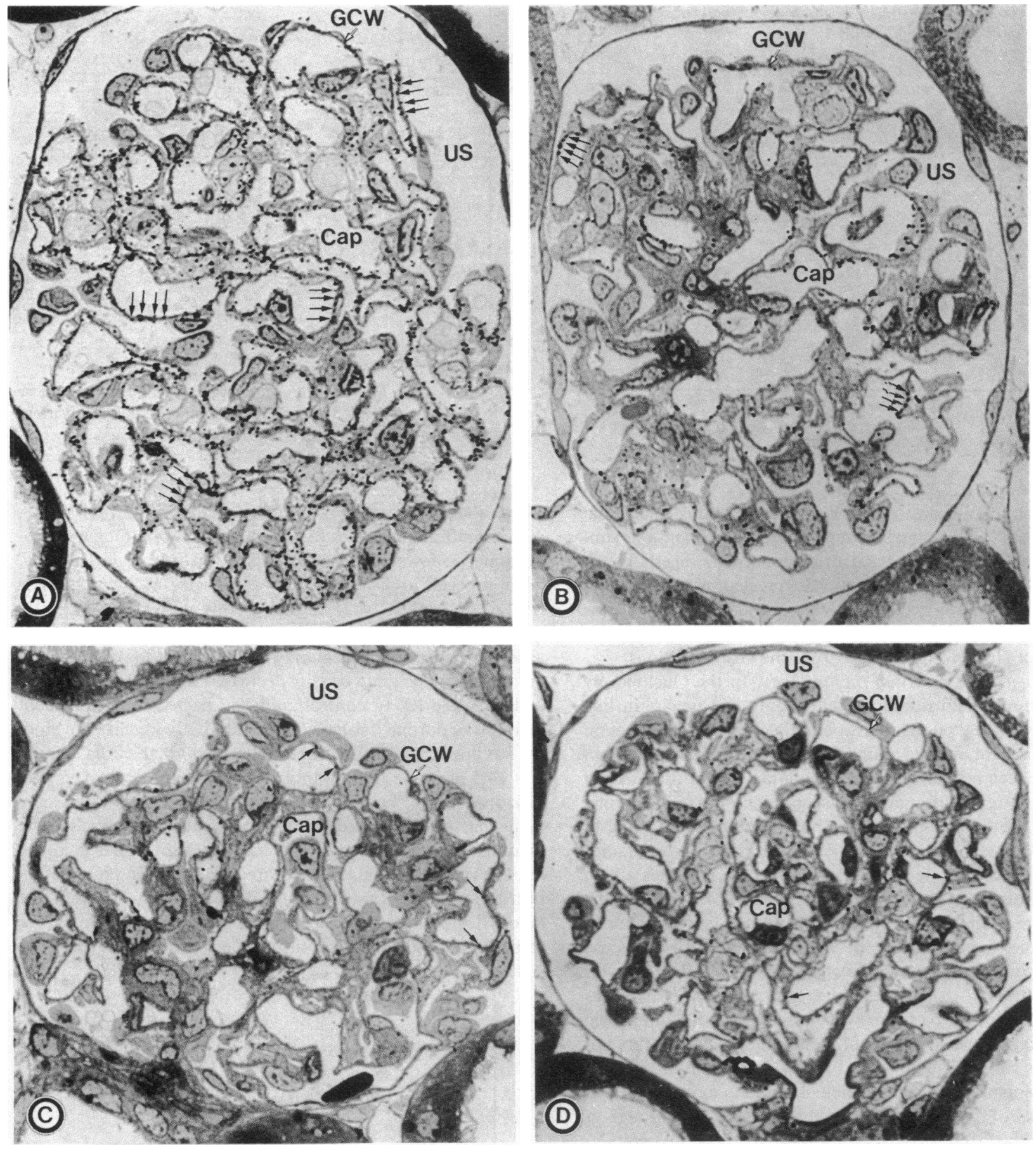

Figure 7. Light microscopic autoradiograms of the glomeruli from kidneys of animals that received $25 \mathrm{mg}(A), 2.5 \mathrm{mg}(B)$, and $0.25 \mathrm{mg}$ $(C)$ of radioiodinated antibody. $D$ is from the control animal injected with $25 \mathrm{mg}$ of radioiodinated normal $\mathrm{IgG}$. Note that at a dose of 25

$\mathrm{mg}(A)$ all the capillary loops show maximum-uniform binding of the antibody (arrows) and is dramatically different from the control $(D)$. $U S$, urinary space; $G C W$, glomerular capillary wall; Cap, capillary lumen. $\times 750$.

with the antigenic sites of the GBM after radioiodination procedures, and $(b)$ the radioactivity measured on the whole kidney specimens reflect exclusively the ${ }^{125}$ I-antibody bound to the glomeruli and almost neglible nonspecific binding of normal $\operatorname{lgG}$ fraction.

Morphologic studies of nephritogenicity experiments. By light microscopy, no significant pathologic changes were seen in the control animals injected with normal rabbit serum. In contrast,

numerous PMNs were seen in the renal glomerular capillary lumina $1 \mathrm{~h}$ after the intravenous administration of anti-HS-PG antibody. In some glomeruli, even 4-5 PMNs could be visualized. From $1 \mathrm{~d}$ onwards, only occasional PMN was observed in the glomerular capillaries. The other discernible glomerular changes included mild mesangial hypercellularity and focal increase in the mesangial matrices beginning with the sixth day and gradually accentuating with progression of time. 
Table II. Grain Density Distribution of Radioiodinated Antibody on the Glomerular Capillary Wall

$\left.\begin{array}{lr}\hline \text { Dose* } & \multicolumn{1}{l}{\text { Mean } \pm \text { SD }} \\ \hline m g & \\ 0.0625 & 0.66 \pm 0.19 \\ 0.1250 & 0.71 \pm 0.25 \\ 0.2500 & 1.32 \pm 0.55 \\ 2.5000 & 3.04 \pm 0.63 \\ 25.0000 & 12.78 \pm 2.63\end{array}\right\} \S$

* $\mathrm{mg} / 50 \mathrm{~g}$ body weight.

$¥$ Not significant.

$\S P$ value $<0.001$

Immunofluorescent microscopic findings are summarized in Table III. Intense uniform linear immunofluorescence of rabbit IgG was observed on the GBMs within $1 \mathrm{~h}$ (Fig. $8 \mathrm{C}$ ) after intravenous administration of the antibody. The intensity of staining seemed to be similar at a wide range of concentrations of the antibody delivered to the animal $(5-50 \mathrm{mg} / 100 \mathrm{~g}$ body weight), which indicates a definitive saturation of binding sites of the GBM with the amount of antibody $(50 \mathrm{mg})$ used in the current experiments. The fluorescence persisted with an almost identical pattern up to $24 \mathrm{~d}$ (Fig. $8 \mathrm{D}$ ), although the degree of staining regressed somewhat during this period. At no time did we observe any mesangial staining. The tubular basement membranes and Bowman's capsule did not fluoresce. Rat $\mathrm{C}_{3}$ also showed a linear pattern of fluorescence (Fig. $8 E$ ); however, the intensity was much less as compared with rabbit IgG. In addition, rat $\mathrm{C}_{3}$ staining was transient, it was highest at $1 \mathrm{~h}$ after injection of the antibody, and appeared in trace amounts at $3 \mathrm{~d}$ (Fig. 8 $F$ ), and completely disappeared by the 10th d. Occasional, focal, and weak immunofluorescence was seen with rat $C_{3}$ in the interstitium and tubular basement membranes in control as well as experimental animals. Rat IgG was negative throughout the course of the experiments. The tubular epithelium was also negative for anti-rat albumin, which indicates that no significant loss of proteins of glomerular origin had occurred. The control animals that received IgG-enriched fraction from normal rabbit serum did not have any reactivity toward rabbit or rat IgG.

Table III. Summary of Immunofluorescent Findings in Experimental Rats

\begin{tabular}{rllll}
\hline & Rabbit IgG* & Rat IgG* & Rat $\mathrm{C}_{3}^{*}$ & Rat albumin \\
\hline $1 \mathrm{~h}$ & $(++++)$ & $(-)$ & $(++)$ & $(-)$ \\
$1 \mathrm{~d}$ & $(++++)$ & $(-)$ & $(++)$ & $(-)$ \\
$3 \mathrm{~d}$ & $(++++)$ & $(-)$ & $(+)$ & $(-)$ \\
$6 \mathrm{~d}$ & $(++++)$ & $(-)$ & $( \pm)$ & $(-)$ \\
$10 \mathrm{~d}$ & $(++++)$ & $(-)$ & $( \pm)$ & $(-)$ \\
$15 \mathrm{~d}$ & $(++++)$ & $(-)$ & $(-)$ & $(-)$ \\
$24 \mathrm{~d}$ & $(+++)$ & $(-)$ & $(-)$ & $(-)$
\end{tabular}

* Glomerular basement membrane immunofluorescence.

‡ Tubular epithelial immunofluorescence.
Electron microscopy of the renal glomeruli of the control rats revealed no significant ultrastructural alterations except for minimal swelling of the endothelial cells. The glomerular alterations in the experimental group included cellular as well as extracellular matrical changes. Soon after the introduction of the antibody, glomerular infiltration of PMNs was observed. It was most pronounced at $1 \mathrm{~h}$ (Fig. 9) and gradually diminished by $1 \mathrm{~d}$. By the third day, occasional PMN was seen in the glomerular capillaries. Most of the PMN were apposed to the inner lining of the capillaries with their cytoplasmic pseudopods extending through the endothelial fenestrae and adhering to the GBM (Fig. $10 A$ and $B$ ). Focal endothelial detachments with a substantial portion of the PMN cytoplasm in direct contact with the GBM were seen (Fig. $10 \mathrm{~A}$ ). The endothelial cells were swollen and had marked increase in the cytoplasmic ribosomes and endoplasmic reticulum. The GBM contained regularly-spaced electron-dense deposits in the lamina rara interna (LRI) and lamina rara externa (LRE) of the GBM. The visualization of these deposits was enhanced by tannic acid fixation (Figs. $10 B$ and $11 A$ ). The mesangial matrix appeared to be free of deposits. Extraglomerular basement membranes, i.e., those of Bowman's capsule and of tubules, did not contain any deposits. No deposits were seen in the control animals. The tubular epithelium did not exhibit any unusual amounts of lysosomal or protein absorption droplets. From the sixth day onward, there were progressive alterations in the mesangium as well as in the GBM. There was a mild mesangial hypercellularity with minimal increase in the mesangial matrices and slight thickening of the GBMs. Their rough endoplasmic reticulum and Golgi elements were somewhat prominent. By the 15 th day, the changes were quite dramatic. The monocytic infiltration was evident (Fig. 12 $A$ and $B$ ). The mesangial matrices were much increased and a few capillaries had mesangial interposition (Fig. $12 \mathrm{~B}$ ). The GBMs were focally thickened and had a knobby appearance due to numerous non-electron-dense subepithelial humps (Fig. 12 $A$ and $B$ ). By the 24th day, the mesangial hypercellularity progressed to the point of almost simulating, at places, a focal proliferative glomerulonephritis (Fig. $13 \mathrm{~A}$ ). The GBM alterations were further accentuated. The knobby appearance of the GBM could be observed in more than $50 \%$ of the capillary loops (Fig. $13 B$ ). The epithelial cells were somewhat swollen with prominent rough endoplasmic reticulum and Golgi elements. They had focal disruption in the organization of their foot processes associated with cytoskeletal changes in the form of aggregation of actin filaments. The dilated cisternae of endoplasmic reticulum of epithelial cells often contained electron-dense material with lamellated sheets, which was highly reminiscent of basement membrane (insets of Fig. $13 A$ and $B$ ). The electron-dense deposits could still be visualized but to a lesser degree in the LRI and LRE of the GBM. The endothelial cells were also somewhat swollen and prominent and had increased cytoplasmic ribosomal contents. A few monocytes were seen either freely floating in the capillary lumina or attached to the endothelium. In some capillary loops monocytes were attached to the basement membranes where endothelium had exfoliated. In addition, a few platelets and fibrin thrombi were observed in the capillary lumina.

Urinary proteins. Mean urinary proteins were $<2 \mathrm{mg} /$ day per $100 \mathrm{~g}$ body weight both in experimental and control groups of animals (Table IV), which suggests a lack of proteinuric response to the administration of normal rabbit serum or IgG enriched fraction of anti-HS-PG. 

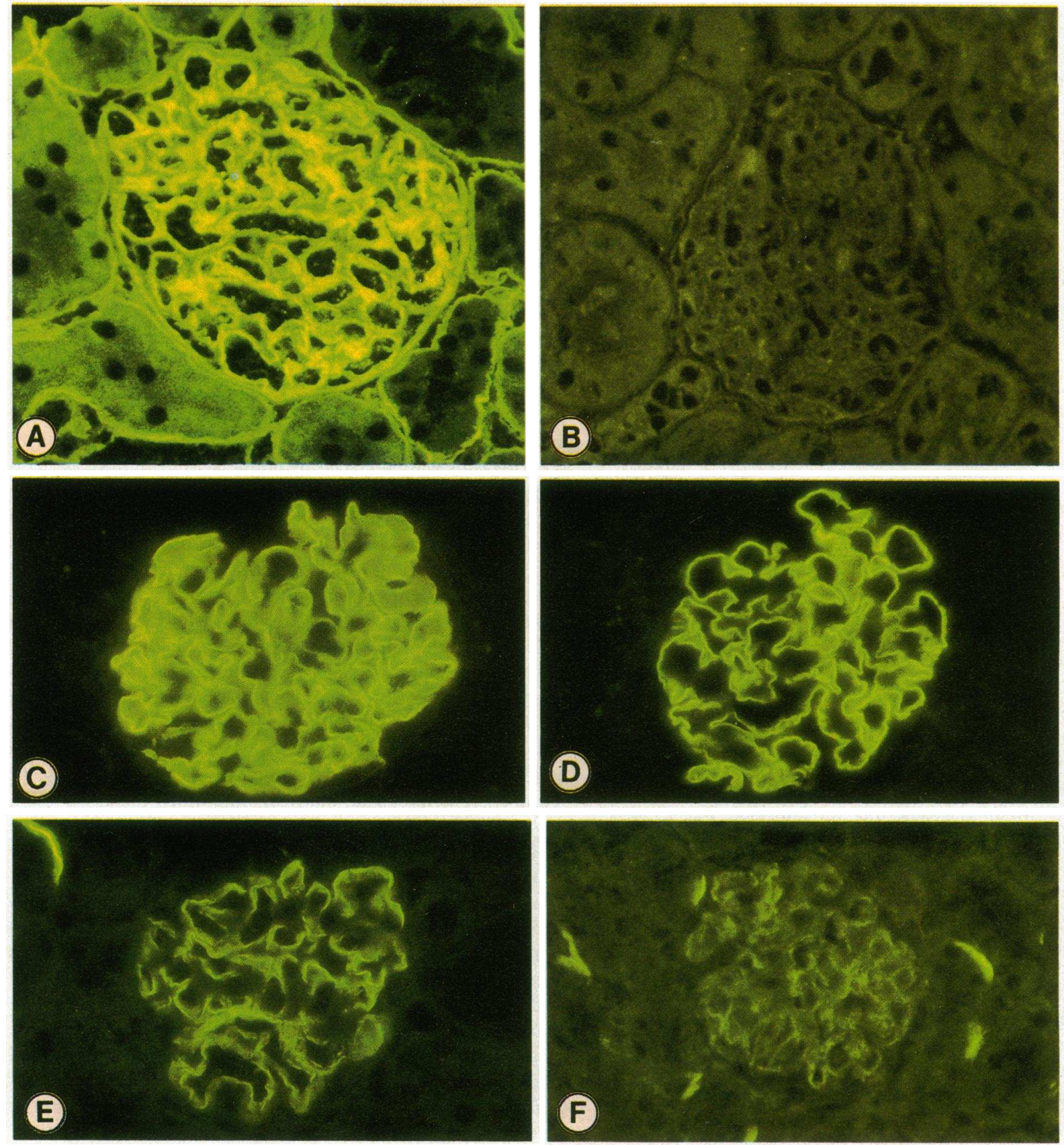

Figure 8. Indirect immunofluorescent microscopy of cryostat sections incubated either with anti-HS-PG $(A)$ or IgG-enriched fraction of serum $(B)$, followed by reincubation with FITC conjugated anti-rabbit IgG. Linear fluorescence of basement membranes of the glomerulus and tubules is observed. The remaining micrographs represent direct immunofluorescence of sections of kidney from animals administered

\section{Discussion}

In this study we have shown an authentic isolation of the coreprotein of HS-PG from purified fractions of GBMs and preparation of specific antibodies with precise reactivity toward the mammalian basement membranes. In addition, we have shown certain nephrotoxic effects of the anti-HS-PG antibodies, though their nephritogenic potential was somewhat weaker than that with anti-HS-PG and killed at $1 \mathrm{~h}(C$ and $E), 3 \mathrm{~d}(F)$, and $24 \mathrm{~d}(D)$ later. $C$ and $D$ are the sections stained with FITC anti-rabbit IgG, while $E$ and $F$ were stained with FITC anti-rat $\mathrm{C}_{3}$. The fluorescence with anti-rabbit IgG reacting with anti-HS-PG persisted up until $24 \mathrm{~d}$ $(D)$, while anti-rat $C_{3}$ regressed to a large extent by the third day $(F)$.

observed with nephrotoxic antibodies directed against the whole GBM (2-19).

The GBM, as a large macromolecular complex, has been known for some time to be highly immunogenic and its antibodies serve as quite potent nephritogens $(1,3-6)$. There are several known major glycoproteins (20-24) that are responsible for the inherent structural makeup of the GBM; and the heparan sulfate, an additional integral component, was discovered a few 


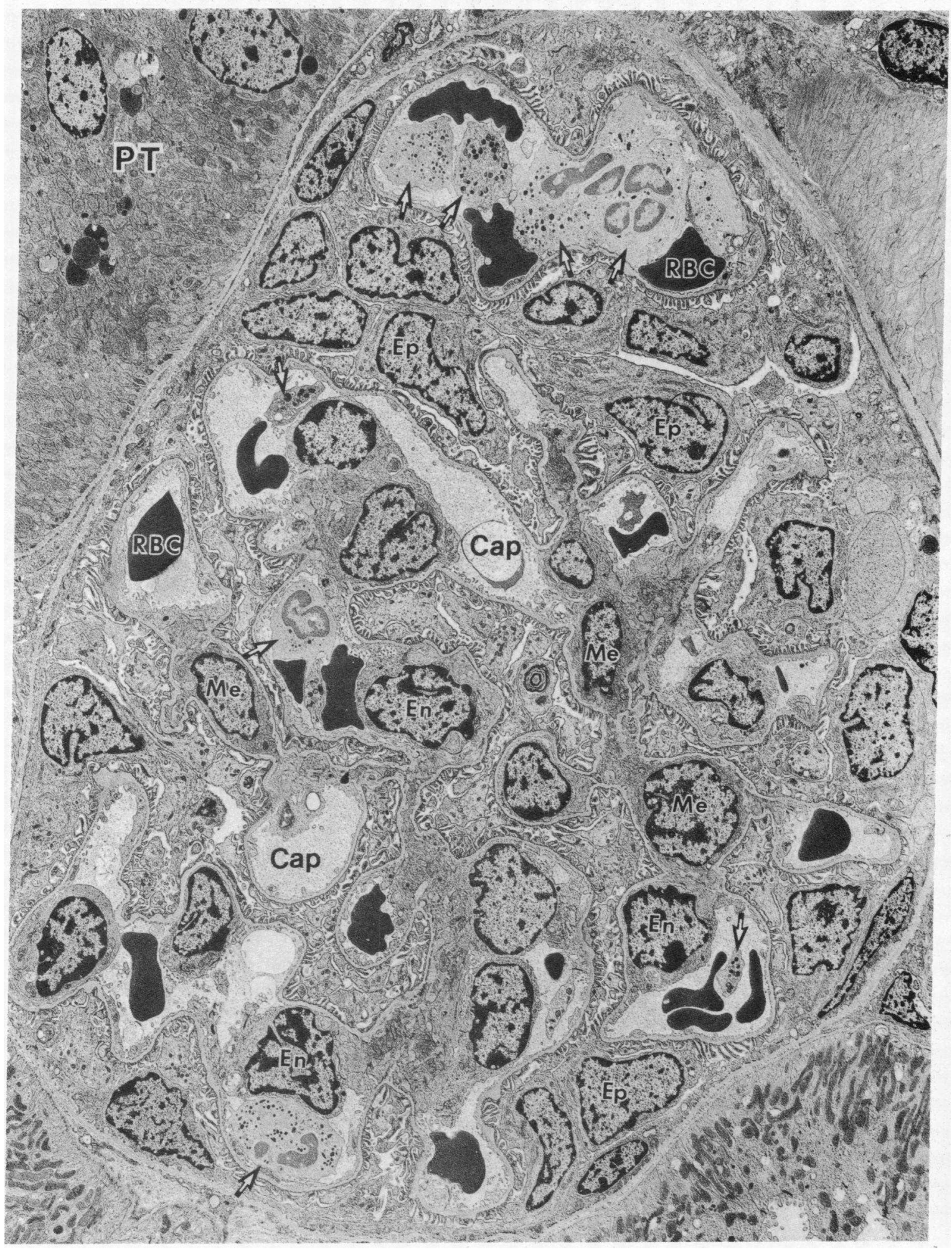

Figure 9. Low power electronmicrograph of the glomerulus taken from an animal administered intravenously with anti-HS-PG antibody and killed $1 \mathrm{~h}$ later. Infiltration by polymorphonuclear leukocytes (arrows) is observed in many capillaries (Cap). No increase in the protein

years ago (50). The exploration of immunogenicity of the HSPG and nephritogenic potential of its antibodies was hindered by the fact that it is present in minute amounts in the GBM absorption droplets is seen in the proximal tubular epithelium $(P T)$. The basement membrane of capillary loops is uniformly thin. Ep, epithelium; $E n$, endothelium; $M e$, mesangium; $R B C$, erythrocytes. Glutaraldehyde immersion fixation. $\times 3,000$.

(25). Secondly, the core-protein of proteoglycans is extremely susceptible to proteolysis and would be readily degraded by contaminating proteases during preparations of the GBM, thus ren- 


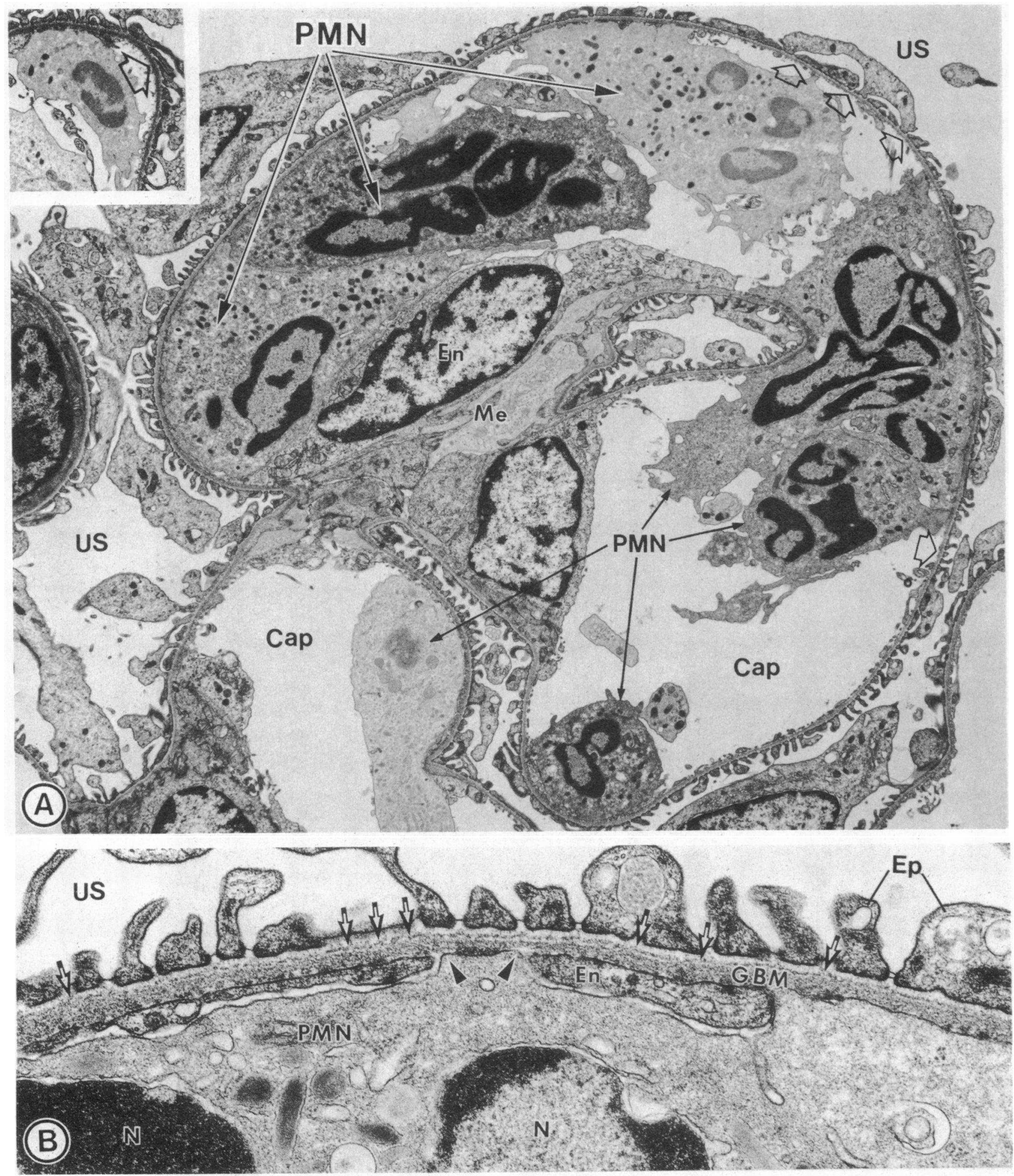

Figure 10. Electronmicrographs of portions of the glomeruli from animal killed at $1 \mathrm{~h}$ after administration of the antibody. $(A)$ Note the accumulation of polymorphonuclear leukocytes $(P M N)$ in the capillary lumena (Cap) and adhering to the GBM and causing exfoliation of the endothelium $(E n)$ in focal regions (open arrows, including inset). $(B)$ the pseudopods (arrow heads) of PMN are seen extending toward the

dering the feasibility of its isolation almost impossible (26). This investigation is the first description of successful isolation of the core-protein of HS-PG directly from the purified fractions of
GBM through the endothelial fenestrae. An electron-dense layer is seen in the laminae rara externa of the GBM where antibody has localized (arrows). Me, mesangium; $E p$, epithelial foot processes; $U S$, urinary space; $N$, nucleus of the PMN. Tannic acid glutaraldehyde perfusion fixation. $A$ and inset, $\times 5,500 ; B, \times 28,000$.

the nonradiolabeled GBMs, and has almost the same amino acid composition as that isolated from whole glomeruli (26). In view of the fact that the core-proteins isolated from either whole 

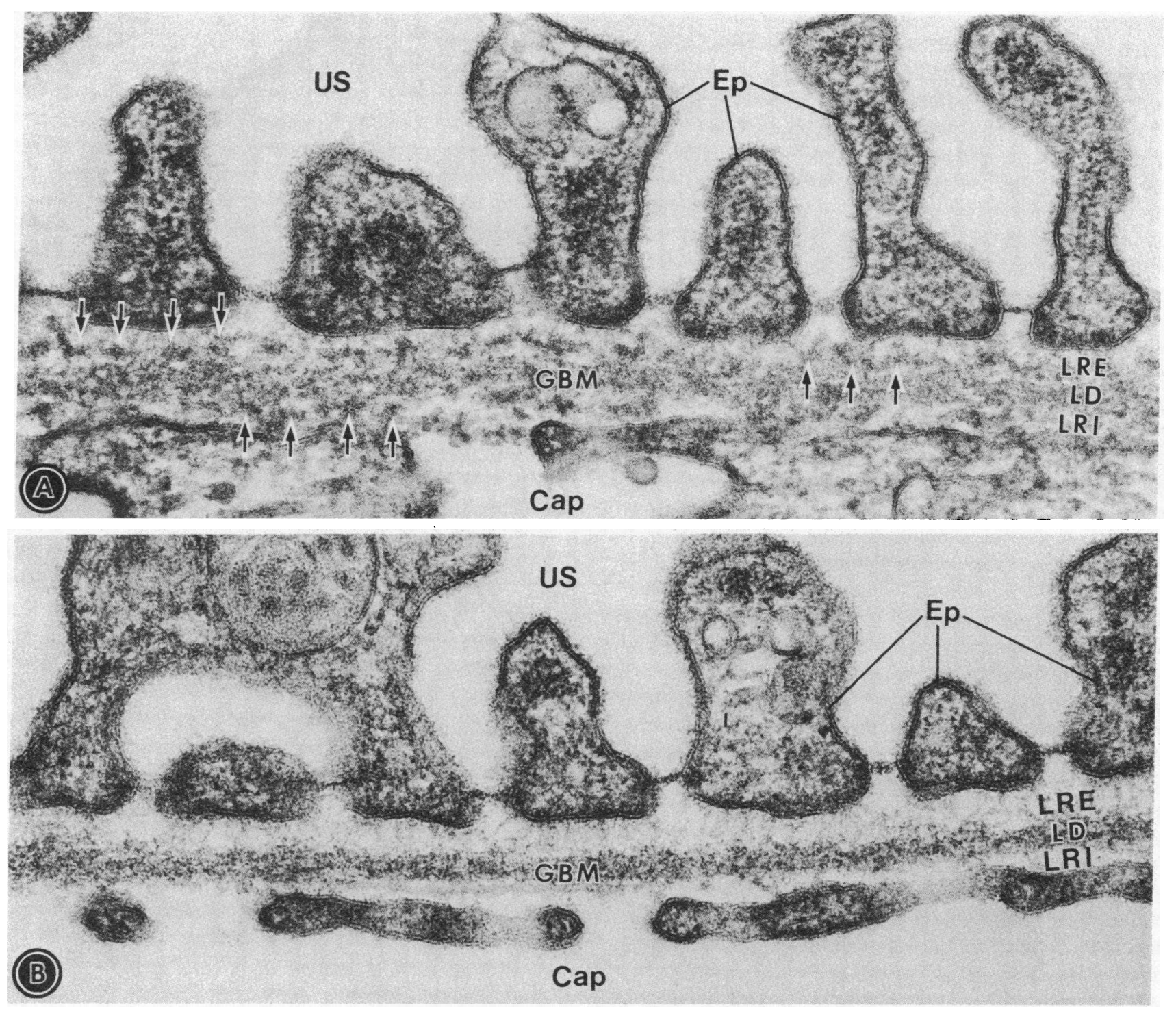

Figure 11. High power electronmicrographs of the glomerular capillary loops of animals given either IgG-enriched fraction of anti-HS-PG $(A)$ or of normal serum $(B)$ and killed $1 \mathrm{~h}$ later. Numerous electrondense deposits (arrows) are seen in the LRI and LRE of the GBM in the animals that received anti-HS-PG $(A)$. No deposits are seen in the animals that received normal $\operatorname{IgG}(B) . U S$, urinary space; $E p$, epithelial foot processes; $L D$, lamina densa; $C a p$, capillary lumen. Tannic acid glutaraldehyde perfusion fixation. $\times 100,000$. glomeruli or GBMs have similar chemical compositions, it seems appropriate and reasonable to isolate HS-PG from whole glomeruli, where the yield could be easily increased by five- to tenfold. For reference purposes, we should mention that its amino acid composition has no similarities to the HS-PG isolated from Engelbreth-Holm Swarm (EHS)-sarcoma (51) or other basement membrane high molecular weight glycoproteins $(23,24)$.

The preparation of polyclonal antibodies was further impeded by the fact that the core-protein is somewhat weakly immunogenic. We had to use a large amount of antigen (3-4 $\mathrm{mg}$ per booster injection) over a period of at least 6-8 wk before an adequate immune response could be detected by Ouchterlony immunodiffusion method (a conventional procedure employed in past investigations in this particular field) $(4,5,12)$. Although the whole GBM is highly immunogenic, the immunogenicity of its individual components seems to be ill-defined (4-6). It is conceivable that, similar to our experience, the other antigenic components of the GBM may also be weakly immunogenic. Nevertheless, a successful preparation of specific antibodies directed against the core-protein of the GBM has enabled us to carry out detailed nephritogenicity experiments. Also, with the availability of these antibodies, future experiments are likely to be readily feasible.

These antibodies exhibit cross-reactivity toward tubular, vascular, and alveolar basement membranes, which indicates the presence of similar types of proteoglycans (HS-PG) in such tissues with core-proteins sharing the same antigenic determinants. Incidentally, there does not appear to be any cross-reactivity with the cell surface associated proteoglycans of liver (author's unpublished results). Moreover, the amino acid composition of the core-protein of hepatic HS-PG differs remarkably from that of the GBM (52). Henceforth, perhaps in this very context, antibodies to core-proteins of HS-PG isolated from extraglomerular membranes may not be suitable for the nephri- 

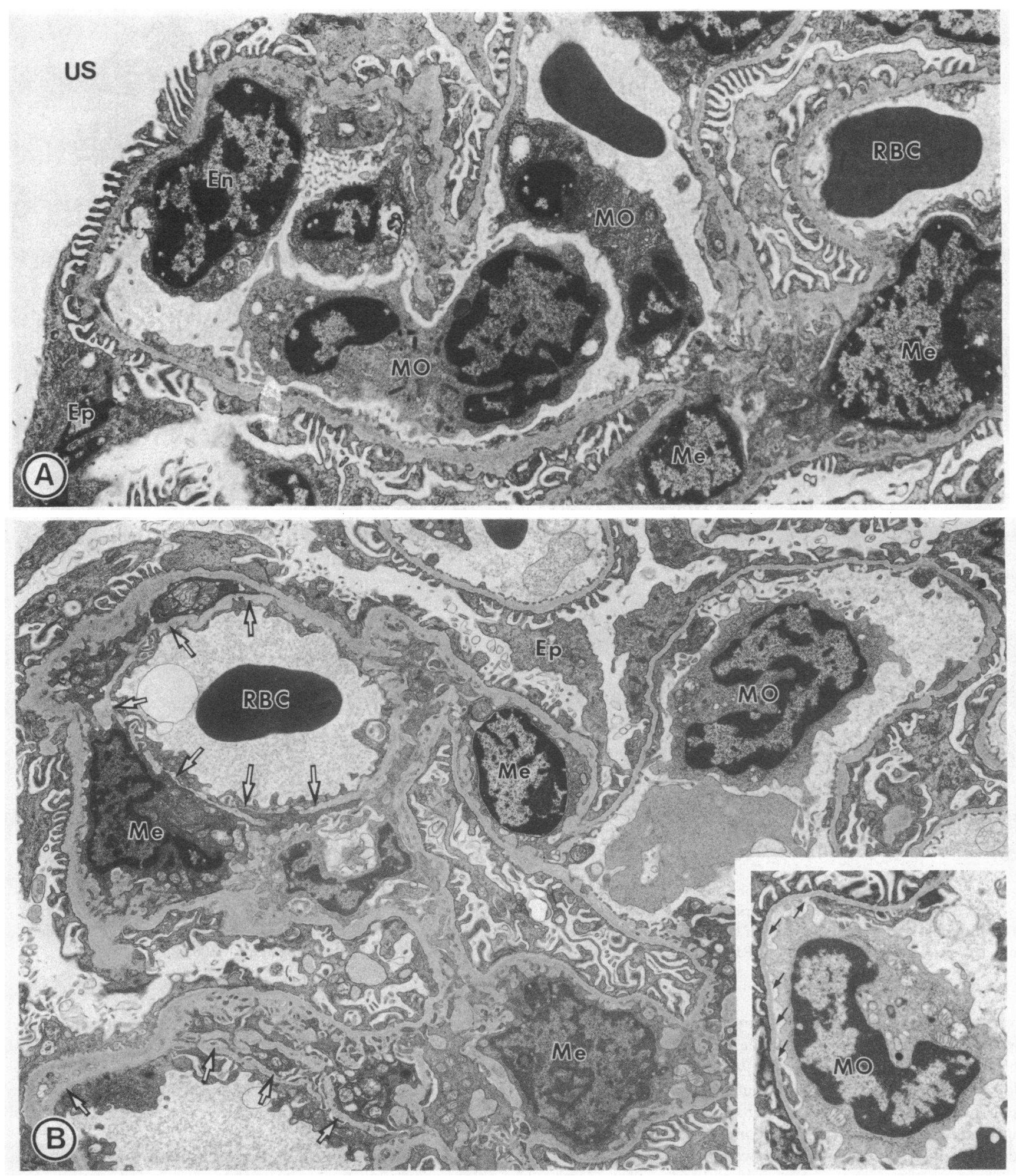

Figure 12. Electronmicrographs of the portions of the glomeruli from animals sacrificed on the 15th day after administration of the antibody. Monocyte $(M O)$ infiltration is observed along with focal thickening of the basement membranes. Moderate mesangial cell $(\mathrm{Me})$ hypercellularity and increase in the mesangial matrices is seen. Some of

togenicity experiments. The antibodies under current investigation also do not react with the other basement membrane components as well as with the collagenase or pronase or tryptic the capillary loops exhibit mesangial interposition (arrows). There are focal detachments of the endothelium where monocytes $(M O)$ come in contact with the GBM (arrows in inset). En, endothelium; $E p$, epithelium; $U S$, urinary space. Glutaraldehyde immersion fixation. $A$ and inset, $\times 7,000 ; B, \times 5,000$.

digests of the GBM. In addition, the antibody reactivity with the core-protein of HS-PG is readily lost when the latter is subjected to even a very mild degree of proteolysis. All in all, it 

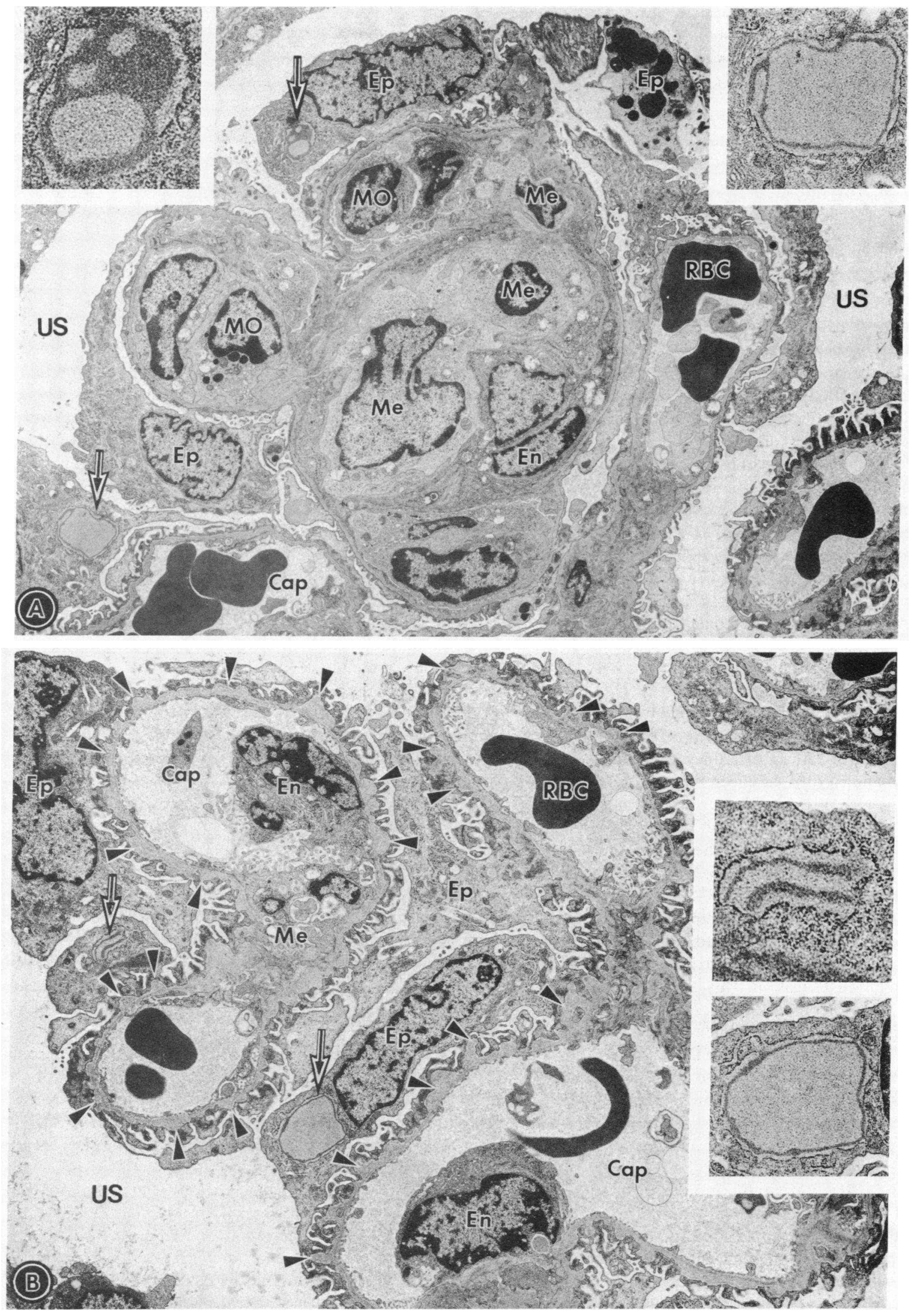

Figure 13. Electron-micrographs of the portions of the glomeruli from animals killed on the 24th day after administration of the antibody. $(A)$ Focal proliferative lesions composed of mesangial $(\mathrm{Me})$, endothelial $(E n)$, and monocytic $(M O)$ cells are observed. Focal loss of organization of epithelial $(E p)$ foot processes is seen. Many cisternae of the rough endoplasmic reticulum (arrows and insets) contain electrondense lamellated material. $(B)$ More than $50 \%$ of the capillary loops exhibit dramatic focal knob-like thickening of the basement mem- brane (arrow heads) along with increase in the mesangial matrices. The plicated sheets of electron-dense material reminiscent of glomerular basement membrane are seen in the dilated cisternae of the rough endoplasmic reticulum (arrows and insets). Cap, capillary lumen; $U S$, urinary space. Glutaraldehyde immersion fixation. $A, \times 3,500$; left inset of $A, \times 17,000$; right inset of $A, \times 8,500 ; B, \times 4,000$; top inset of $B, \times 20,000$; bottom inset of $B, \times 10,000$. 
Table IV. Urinary Protein Excretions* at Various Time Intervals of the Experiments

\begin{tabular}{lllllll}
\hline Animals & $0 \mathrm{~d}$ and before & $1 \mathrm{~d}$ & $3 \mathrm{~d}$ & $6 \mathrm{~d}$ & $10 \mathrm{~d}$ & $15 \mathrm{~d}$ \\
\hline Controi & $0 \pm 0 \ddagger$ & $0.1 \pm 0.1$ & $0 \pm 0$ & $0 \pm 0$ & $0.7 \pm 0.3$ & $0.5 \pm 0.4$ \\
Experimental & $0 \pm 0$ & $0.5 \pm 0.3$ & $0 \pm 0$ & $0 \pm 0$ & $0.1 \pm 0.1$ & $1.2 \pm 0.8$ \\
\hline
\end{tabular}

* $\mathrm{mg} / 24 \mathrm{~h}$ per $100 \mathrm{~g}$ body weight. $\ddagger$ Mean \pm SEM of animals in each group.

appears that these antibodies are highly specific and well befitted for the nephritogenicity experiments.

The nephritogenicity experiments were carried out with relatively larger doses of antibody so that the nephrotoxic effects would be fully evolved. The anticipated concern that small doses of the antibody may not produce consistent results relates to the fact that the antibodies to other glycoproteins such as laminin or type IV collagen, when administered in small amounts, failed to activate complement, induce proteinuria, or significant pathologic changes in the glomerulus (27-29). Except for the proteinuria, activation of the complement and remarkable progressive morphologic lesions were elicited in our studies. The mild degree of proteinuria, observed in previous studies as a result of administration of anti-type IV collagen or laminin antibodies, is questionable since factors such as age, sex, and diet, which influence the urinary protein excretions, were not taken into proper consideration.

In the past, the degree of nephritogenic proteinuric response has been correlated with the amount of antibodies fixed to the kidney (48). Usually, 175-250 $\mu \mathrm{g}$ of kidney fixed antibodies, directed against the whole GBM, has been reported to induce a dramatic proteinuric response extending from heterologous to autologous phase (48). However, at a comparable level of binding of HS-PG antibody (150-225 $\mu \mathrm{g}$ ), no significant proteinuria was observed, which thereby indicates its weaker nephritogenic potential. Although the absolute amount (150-225 $\mu \mathrm{g})$ and percent binding (0.8-1.6\%) of HS-PG antibody were comparable to the binding characteristics of other GBM antibodies (27, 48, 49); still, it is difficult to correlate their nephrotoxicity with the results obtained in the present investigation. This is due to the fact the molecular weight, subunit composition, configuration, and antigenic determinants of various glycoproteins of the GBM vary considerably, and thus would have different antibody binding characteristics. In this investigation, despite a lack of significant proteinuric response, the ultrastructural changes seem to be quite impressive and perhaps more pronounced than those seen in the classical form of Masugi nephritis $(10,12)$.

The early phase lesions included the antibody binding in the LRE and LRI of the GBM, PMN infiltration, exfoliation of the endothelium, and deposition of $\mathrm{C}_{3}$ along the capillary walls of the glomerulus. These changes seem to correspond to the lesions described for the heterologous phase of nephrotoxic nephritis. Nevertheless, the changes seem to be much more accentuated in the current model system. Interestingly enough, one could readily demonstrate the presence of antibody in the LRE and LRI in a pattern that is reminiscent of binding of immune-complexes $(40,53)$ to the anionic sites of the $\operatorname{GBM}(31,54,55)$. The binding of this particular antibody to the LRE and LRI is more or less a further attestation to the fact that HS-PG residues are indeed concentrated in these strategic locations of the GBM. The complement deposition in a similar pattern and location, most likely, is secondary to or follows the initial binding of the antibody. The PMN infiltration probably represents a response to the deposition of antibody and is possibly due to concomitant activation of the complement. In such a cascade of events, severe structural damage to the capillary wall would be expected with ensuing proteinuria; the latter could conceivably be due either to hydrolysis of the GBM (11) or to exfoliation of glomerular endothelium (13) by the PMN enzymes. The lack of proteinuric response in the present model system despite the well established changes, i.e., infiltration of PMN and endothelial exfoliation, is somewhat intriguing and remains unexplained. Henceforth, further experimental manipulations of this model system are necessary to understand the perplexing observations. However, what remains factual is that the occupation (blocking? neutralization?) of anionic sites rich in HS-PG by the antibody per se does not cause proteinuria. Furthermore, the lack of proteinuric response in the presence of exfoliated endothelium with PMN adherence to the GBM may suggest a more emphatic role of peripheral layers of the glomerular capillary wall $(30,56,57)$ and extraglomerular hemodynamic determinants of permselectivity $(30,58)$.

The monocytic infiltration in the glomerular capillaries seen from mid-time period onward resembles, to a certain extent, what is observed during the time frame of the post-heterologous/ autologous phase of nephrotoxic nephritis. The magnitude of such a cellular response seems to be the same as that reported in the traditional model of NTN $(17,18)$. In this phase of NTN, the monocytic infiltration with their adherence to the GBM in the exfoliated endothelial regions is usually associated with proteinuria $(15,18)$. Irrespective of such a firm relationship between glomerular alterations and enhanced transcapillary passage of proteins, we did not observe any significant proteinuria. Conceivably, in the present experiments there may not be sufficient monocytic accumulation; henceforth, cellular response may have to be accentuated to establish a better correlation between the morphologic and physiologic changes in a manner similar to what had been described in the accelerated form of NTN experimental model (18).

The dramatic glomerular changes were seen in the latter part of the disease process and appeared to be independent of the complement activation/deposition or humoral response. The lack of humoral response and autologous IgG and $C_{3}$ in the GBM most likely indicate that the changes, both cellular and extracellular, do not bear stringent resemblances to the autologous phase of NTN (16-19). The proliferative response of the mesangial cell and to a certain degree of endothelium may be due to a sustained stimulus, which may be by the translocation of minute amounts of antibody into the mesangium from the peripheral capillaries over a period of several days. With the sustained stimulus to the glomerular cells, a substantial increase in synthesis of mesangial matrix is anticipated. The matrix pro- 
duction may sometimes be overwhelming in certain capillary loops with consequential mesangial interposition-a change reminiscent of membrano-proliferative glomerulonephritis (59).

Similarly, hypertrophic or stimulatory organelle changes were observed in the visceral epithelium of the glomerulus. The changes were in the form of prominent rough endoplasmic reticulum and Golgi apparatus. In addition, material resembling plicated sheets of basement membrane was seen very often in the dilated cisternae of the rough endoplasmic reticulum. Except for the latter substructures contained within the rough endoplasmic reticulum, the other changes do not typify NTN and have not been documented in previous investigations (9-13). The ready presence of lamellated substructures $(60)$ in the epithelial cytoplasm and remarkably impressive knob-like thickening of the GBM may suggest stepped-up synthesis of basement membrane glycoproteins. Alternatively, there may be defective degradation or organization of the basement membrane either due to the mere persistent presence of anti-HS-PG antibody in the GBM or to some undefined loss of regulatory control of synthesis/degradation by visceral epithelium, and perhaps also by the endothelium of the glomerulus. These considerations are speculative in nature and extensive investigatory efforts would be required to delineate the pathogenesis of such lesions. However, it is highly suggestive from the ultrastructural changes observed here that the visceral epithelium plays a pivotal role in synthesis/degradation and turnover of the GBM in a mature glomerulus.

In summary, another model that includes certain features of NTN is presented. It resembles NTN in some aspects, while differing from NTN in other aspects. Perhaps the accentuated form of NTN in this model may be useful in delineating some of the immunological as well as nonimmunological pathogenetic mechanisms in renal glomerular disease processes.

\section{Acknowledgments}

We are thankful for the secretarial assistance provided by Jeannette Sanders. This research was supported by National Institutes of Health grant AM 28492. Dr. Kanwar is a recipient of Research Career Development Award AM 01018.

\section{References}

1. Krakower, C. A., and S. A. Greenspon. 1951. Localization of the nephrotoxic antigen within the isolated glomerulus. Arch. Pathol. 51: 629-639.

2. Masugi, M. 1934. Über die experimentelle Glomerulonephritis durch das spezifische Antinierenserum. Ein Beitrag zur Pathogenese der diffusen Glomerulonephritis. Beitr. Pathol. Anat. Allg. Pathol. 92: 429-446.

3. Nicholes, B. K., C. A. Krakower, and S. A. Greenspon. 1973. The chemically isolated lamina densa of the renal glomerulus. Proc. Soc. Exp. Biol. Med. 142:1316-1321.

4. Kefalides, N. A. 1972. The chemistry of antigenic components isolated from glomerular basement membrane. Connect. Tissue. Res. 1: 3-13.

5. Marquardt, H., C. B. Wilson, and F. J. Dixon. 1973. Isolation and immunological characterization of human glomerular basement membrane antigens. Kidney Int. 3:57-65.

6. Wilson, C. B. 1981. Nephritogenic antibody mechanisms involving antigens within the glomerulus. Immunol. Rev. 55:257-297.

7. Unanue, E. R., and F. J. Dixon. 1964. Experimental glomerulonephritis. IV. Participation of complement in nephrotoxic nephritis. $J$. Exp. Med. 119:965-982.
8. Cochrane, C. G., E. R. Unanue, and F. J. Dixon. 1965. A role of polymorphonuclear leukocytes and complement in nephrotoxic nephritis. J. Exp. Med. 119:99-116.

9. Winemiller, R., R. W. Steblay, and B. Spargo. 1961. Electronmicroscopy of acute anti-basement membrane serum nephritis in rats. Fed. Proc. 20:408-409.

10. Feldman, J. D., D. Hammer, and F. J. Dixon. 1963. Experimental glomerulonephritis. III. Pathogenesis of glomerular ultrastructural lesions in nephrotoxic serum nephritis. Lab. Invest. 12:748-763.

11. Hawkins, D., and C. G. Cochrane. 1968. Glomerular basement membrane damage in immunological glomerulonephritis. Immunology. 14:665-681.

12. Gang, N. F., and N. Kalant. 1970. Nephrotoxic serum nephritis. Chemical, morphologic and functional changes in the glomerular basement membrane during evolution of nephritis. Lab. Invest. 22:531-540.

13. Shibata, S., H. Sakaguchi, and T. Nagasawa. 1978. Exfoliation of endothelial cytoplasm in nephrotoxic serum nephritis. Lab. Invest. 38:201-207.

14. Unanue, E. R., and F. J. Dixon. 1965. Experimental glomerulonephritis. V. Studies on the interaction of nephrotoxic antibodies with tissues of the rat. J. Exp. Med. 121:697-714.

15. Kühn, K., G. B. Ryan, S. J. Hein, R. G. Glaske, and M. J. Karnovsky. 1977. An ultrastructural study of the mechanisms of proteinuria in rat nephrotoxic nephritis. Lab. Invest. 36:375-387.

16. Hammer, D., and F. J. Dixon. 1963. Experimental glomerulonephritis. II. Immunologic events in the pathogenesis of nephrotoxic serum nephritis in the rat. J. Exp. Med. 117:1019-1034.

17. Shigematsu, H., and Y. Kobayashi. 1971. The development and fate of immune deposits in the glomerulus during the secondary phase of rat Masugi nephritis. Virchows. Arch. Abt. B. Zellpathol. 8:83-95.

18. Schreiner, G. F., R. S. Cotran, V. Pardo, and E. R. Unanue. 1978. A mononuclear cell component in experimental immunological glomerulonephritis. J. Exp. Med. 147:369-384.

19. Unanue, E. R., and F. J. Dixon. 1965. Experimental glomerulonephritis. VI. The autologous phase of nephrotoxic serum nephritis. J. Exp. Med. 121:715-725.

20. Spiro, R. G. 1972. Basement membrane and collagens. In Glycoproteins. A. Gottschalk, editor. Elsevier/North Holland, Amsterdam. Second ed. Part B, 964-999.

21. Kafalides, N. A. 1973. Structure and biosynthesis of basement membrane. Int. Rev. Connect. Tissue Res. 6:63-104.

22. Kefalides, N. A. 1971. Isolation of a collagen from basement membranes containing three identical \& strains. Biochem. Biophys. Res. Commun. 45:226-234.

23. Timpl, R., H. Rhode, G. P. Robey, S. I. Rennard, J. M. Foidart, and G. R. Martin. 1979. Laminin: a glycoprotein from basement membrane. J. Biol. Chem. 254:9933-9937.

24. Carlin, B., R. Jaffe, B. Bender, and A. E. Chung. 1981. Entactin, a novel basal lamina-associated sulfated glycoprotein. J. Biol. Chem. 256:5209-5214.

25. Kanwar, Y. S., and M. G. Farquhar. 1979. Isolation of glycosaminoglycans (heparan sulfate) from glomerular basement membranes. Proc. Natl. Acad. Sci. USA. 76:4493-4497.

26. Kanwar, Y. S., A. Veis, J. H. Kimura, and M. L. Jakubowski. 1984. Characterization of heparan sulfate-proteoglycan of glomerular basement membranes. Proc. Natl. Acad. Sci. USA. 81:762-766.

27. Abrahamson, D. R., and J. P. Caulfield. 1982. Proteinuria and structural alterations in rat glomerular basement membranes induced by intravenously injected anti-laminin immunoglobulin G. J. Exp. Med. 156:128-145.

28. Wick, G., P. U. Muller, and R. Timpl. 1982. In vivo localization and pathological effect of passively transferred antibodies to type IV collagen and laminin in mice. Clin. Immunol. Immunopathol. 23: 656-665.

29. Yaar, M., J. M. Foidart, K. S. Brown, S. I. Rennard, G. R. Martin, and L. Liotta. 1982. Goodpasture-like syndrome in mice induced by intravenous injections of anti-type IV collagen and anti-laminin antibody. Am. J. Pathol. 107:79-91. 
30. Kanwar, Y. S. 1984. Biology of disease. Biophysiology of glomerular filtration and proteinuria. Lab. Invest. 51:7-21.

31. Kanwar, Y. S., and M. G. Farquhar. 1979. Anionic sites in the glomerular basement membrane. In vivo and in vitro localization to the laminae varae by cationic probes. J. Cell. Biol. 81:137-153.

32. Kanwar, Y. S., A. Linker, and M. G. Farquhar. 1980. Increased permeability of the glomerular basement membrane to ferritin after removal of glycosoaminoglycans (heparan sulfate) by enzyme digestin. $J$. Cell. Biol. 86:688-693.

33. Meezan, E., J. T. Hjelle, K. Brendel, and E. C. Carlson. 1975. A simple, versatile non-disruptive method for isolation of morphologically and chemically pure basement membranes from several tissues. Life Sci. 17:1721-1732.

34. Kanwar, Y. S., V. C. Hascall, and M. G. Farquhar. 1981. Partial characterization of newly synthesized proteoglycans isolated from the glomerular basement membrane. J. Cell Biol. 90:527-532.

35. Lowry, O. H., N. J. Rosebrough, A. L. Farr, and R. J. Randall. 1951. Protein measurement with the Folin phenol reagent. J. Biol. Chem. 193:265-275.

36. Warren, L. 1959. The thiobarbituric acid assay of sialic acid. $J$. Biol. Chem. 234:1971-1975.

37. Kanwar, Y. S., L. J. Rosenzweig, A. Linker, and M. L. Jakubowski. 1983. Decreased de novo synthesis of glomerular proteoglycans in diabetes: Biochemical and autoradiographic evidence. Proc. Natl. Acad. Sci. USA. 80:2272-2275.

38. Laemmli, U. K. 1970. Cleavage of structural proteins during the assembly of the head of bacteriophage $T_{4}$. Nature (Lond.). 227:680-685.

39. Linker, A., and P. Hovingh. 1972. Heparinase and heparitinase from flavobacteria. Methods Enzymol. 28:901-911.

40. Gallo, G. R., T. Caulin-Glaser, and M. E. Lamm. 1981. Charge of circulating immune complex as a factor in glomerular basement membrane localization in mice. J. Clin. Invest. 67:1305-1313.

41. Alper, C. A., and A. M. Johnson. 1969. Immunofixation-electrophoresis: a technique for the study of protein polymorphism. Vox. Sang. 17:445-452.

42. Reif, A. E. 1969. Batch preparation of rabbit $\mathrm{G}$ globulin with DEAE-cellulose. Immunochemistry. 6:723-731.

43. Ouchterlony, O. 1958. Diffusion-in-gel methods for immunological analysis. In Progress in Allergy. Vol. V. P. Kallos, editor. Karger, New York. 1-78.

44. Towbin, H., T. Staehelin, and J. Gordon. 1979. Electrophoretic transfer of proteins from polyacrylamide gels to nitrocellulose sheets: procedures and some applications. Proc. Natl. Acad. Sci. USA. 76:43504354.

45. Kanwar, Y. S., and L. J. Rosenzweig. 1982. Clogging of the glomerular basement membrane. J. Cell Biol. 93:489-494.
46. Kanwar, Y. S., M. L. Jakubowski, and L. J. Rosenzweig. 1983. Distribution of sulfated glycosaminoglycans in the glomerular basement membrane and mesangial matrix. Eur. J. Cell Biol. 31:290-295.

47. Hiller, A., R. L. Grief, and W. W. Beckman. 1948. Determination of protein in urine by biuret method. J. Biol. Chem. 176:1421-1429.

48. Unanue, E. R., and F. J. Dixon. 1965. Experimental glomerulonephritis. V. Studies on the Interactions of Nephrotoxic Antibodies with Tissues of the Rat. J. Exp. Med. 121:697-714.

49. Madaio, M. P., D. J. Salant, S. Adler, C. Darby, and W. G. Couser. 1984. Effect of antibody charge and concentration on deposition of antibody to glomerular basement membrane. Kidney Int. 26: 397-403.

50. Kanwar, Y. S., and M. G. Farquhar. 1979. Presence of heparan sulfate in the glomerular basement membranes. Proc. Natl. Acad. Sci. USA. 76:1303-1307.

51. Hassell, J. R., P. G. Robey, H. J. Barrach, J. Wilczek, S. I. Rennard, and G. R. Martin. 1980. Isolation of a heparan sulfate-containing proteoglycan from basement membrane. Proc. Natl. Acad. Sci. USA. 77 4494-4498.

52. Oldberg, A., L. Kjellen, and M. Hook. 1979. Cell-surface heparan sulfate. Isolation and characterization of a proteoglycan from rat liver membranes. J. Biol. Chem. 254:8508-8510.

53. Gallo, G. R., T. C. Glaser, S. N. Emancipator, and M. E. Lamm. 1983. Nephritogenicity and differential distribution of glomerular immune complexes related to immunogen charge. Lab. Invest. 48 : 353-362.

54. Rennke, H. G., R. S. Cotran, and M. A. Venkatachalam. 1975. Role of molecular charge in glomerular permeability: tracer studies with cationized ferritins. J. Cell Biol. 67:638-646.

55. Caulfield, J. P., and M. G. Farquhar. 1976. Distribution of anionic sites in glomerular basement membranes. Their possible role in filtration and attachment. Proc. Natl. Acad. Sci. USA. 73:1646-1650.

56. Ryan, G. B., and M. J. Karnovsky. 1975. An ultrastructural study of the mechanism of proteinuria in aminonucleoside nephrosis. Kidney Int. 8:219-232.

57. Kanwar, Y. S., and L. J. Rosenzweig. 1982. Altered glomerular permeability as a result of focal detachment of the visceral epithelium. Kidney Int. 21:565-574.

58. Brenner, B. M., T. H. Hostetter, and H. D. Humes. 1978. Molecular basis of proteinuria of glomerular origin. N. Engl. J. Med. 298: 826-833.

59. Spargo, B. H., A. E. Seymour, and N. G. Ordonez. 1980. Renal biopsy pathology with diagnostic and therapeutic implications. John Wiley and Sons, Inc., New York. 120-151.

60. Andres, G. A., C. Morgan, K. C. Hsu, R. A. Rifkind, and B. C. Seegal. 1962. Electron microscopic studies of experimental nephritis with ferritin-conjugated antibody. J. Exp. Med. 115:929-936. 